\title{
Repetitive strain injury in the newspapers
}

\author{
Guy Harvey
}

On Friday, 29 October 1993, many newspapers reported that the courts had decided not to award compensation to a man who suffered from repetitive strain injury (RSI). All Britain's national dally papers except the Sun and the Star contained articles, most of the papers placing emphasis on the controversy surrounding the diagnosis of RSI: the Financial Times, the Daily Telegraph and The Guardian had major articles debating the existence of the disorder. An article in the Telegraph headlined 'Doctors are divided' went on: "Some doctors say the pain is real, others believe it is psychological and the discomfort is all in the mind." Other papers quoted the poorly reasoned arguments of union officials who opposed the ruling. The Times reported a member of the GMB General Union as saying that world famous companies would not have already paid compensation to union members "because of figments of their imagination". The Telegraph quoted a union health and safety officer as saying, "Anyone who knows anything about anything in the medical profession and the employment world knows that RSI is a real condition." The Guardian gave the opposing views of two specialists; one saying that "cramped postures", "repetitive work" and "stress" were the cause, and the other saying that workers who complain were "malingerers, fakes and fraudsters".

This debate was emphasised, it seemed, at the expense of two more complex arguments. The first was that it was the term RSI and the condition's putative aetiology which were in question, not the suffering of the claimant. The second was that its symptoms probably arose from a combination of physical and psychological causes.

All the papers, except the Telegraph and the Financial Times, omitted to report explicitly that the judge did agree that the claimant was suffering a painful condition. This acknowledgement was important, because without it the reader was left with an impression that the claimant was judged not to have RSI, and therefore not to have pain, so must be malingering or imagining his illness. The overall coverage contained many phrases implying that RSI symptoms were "products of an over-fertile imagination" (Mirror). The

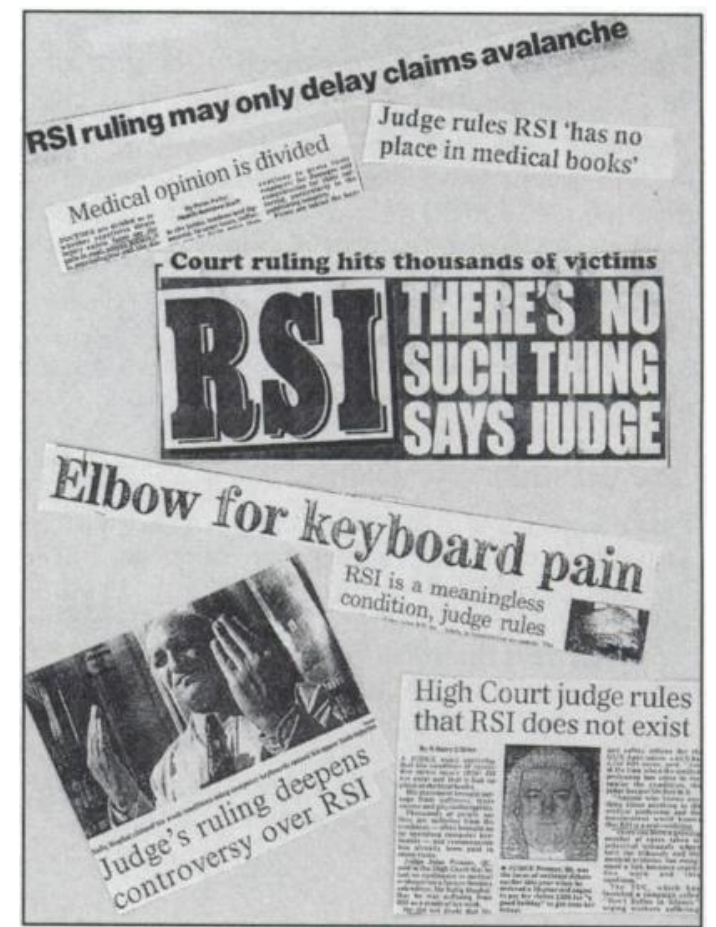

Daily Express said one Australian expert had written "that it was a form of mass hysteria where people with eggshell personalities, who needed to get a grip on themselves, took on the symptoms of workmates".

In fact the Australian experience is that RSI is better thought of as a pain syndrome. Once treatable physical pathology is excluded by relevant investigations, then the management of chronic pain often includes a combination of physical and psychological methods. It is agreed that an essential initial step in this process, is to acknowledge the reality of the pain, and to avoid the fruitless debate between real and imaginary illness which is often at the root of conflict between patient and doctor.

Some papers reported the judge as criticising the claimant's working abilities: for example, 
"Having seen some of his copy I am not surprised he was offered redundancy" (Times), and "colleagues had said the claimant's copy was difficult to read and edit" (Telegraph). The Times said that he "lacked confidence" and "felt persecuted and watched" at work. By linking in this way the judge's "dismissal" of the claimant's lliness with his expressed doubts about the claimant's work and character, the coverage seemed to imply that the sufferer's personality was at fault.

People who suffer with this problem will be affected by the image of the illness represented in the media; this coverage tends to present a negative picture of the psychological aspects of RSI and as a result sufferers may be less accepting of a psychological explanation for their symptoms. As a result, they may miss out on potentially helpful treatments. The attitudes expressed in the media, however, probably reflect wider attitudes in society for which the medical profession is at least partially responsible. It should be the responsibility of the profession as a whole to present a unified and understandable approach to such cases.

Since that controversial ruling in October, a typist who worked at the Inland Revenue has been awarded a large sum as compensation for upper limb pain caused by poor working conditions. The press covered this on 19 January 1994 and The Times was typical in saying that health campaigners and trade unions welcomed the settlement. This lady was quoted, "I hope this helps other people with the same problem" (Telegraph); "this makes rubbish of the judge's statement that it is all in the mind. It was not just in my mind, it was in my hands and wrists and arms," (Daily Mail). But it may be that, in the end, compensation will be achieved at the expense of effective treatment.

Guy Harvey, Registrar in Psychiatry, Meanwood Park Hospital, Tongue Lane, Leeds LS6 4QD

\section{Psychiatry on the air}

\section{Dr Undsey Kemp hangs up her headphones and looks back on her radio days.}

Throughout my psychiatric training I have had the privilege of broadcasting a two hour phone-in programme on one of our local independent radio stations. The programme was broadcast live (without the use even of a time delay) every Sunday evening with a regular presenter, a counsellor who dealt with problems ranging from mental health, legal and relationship difficulties through to providing the address for the local branches of organisations and self-help groups.

I participated in the programme monthly for over six years being part of a team of specialists, one of whom was invited each week to cope with calls and letters on that week's subject. The regular team comprised a GP, a dentist and a lawyer and were supplemented by representatives of the DSS Benefits Office, Relate, the Samaritans, Cruse, dieticians, physiotherapists, drug counsellors and many others who came to give some of their time and expertise. Initially it felt rather overwhelming to be talking to thousands of people simultaneously but once settled in the studio with our counsellor and presenter, it became quite an easy task to talk to the one caller on the telephone or one of the others in the studio and to forget about the audience. This served to reduce the nerveracking aspects of broadcasting but the audience had to be borne in mind so that the answers served not only to help the caller but to educate the other listeners.

My share of the specialist topics tended to include a large number of psychiatric issues. Programmes regularly featured depression, fears and phobias, bereavement, and addictions as well as any other medical issues that callers cared to introduce. As the 'lady doctor' of the team, I seemed to attract many of the family planning and pregnancy items.

Broadcasting has pitfalls and perils but also provides its fair share of amusement. One incident which comes to mind required all the studio team to keep straight faces and avoid each other's gaze for some time, while a male caller spent the first few minutes of his call elucidating the difficulties he and his wife had had with various methods of contraception, resulting in their four children. He then went on to enquire whether he could take his wife for a vasectomy! Like most calls this required little more than simple education as to the differences in male and female sterilisation, the terminology 